\title{
Effectiveness of oral iron to manage anemia in long-term hemodialysis patients with the use of ultrapure dialysate
}

\author{
AKIYASU TSUCHIDA ${ }^{1}$, BISHNUHARI PAUDYAL ${ }^{1,2}$, PRAMILA PAUDYAL $^{2}$, YOSHITAKA ISHII $^{1}$, \\ KEIJU HIROMURA ${ }^{3}$, YOSHIHISA NOJIMA ${ }^{3}$ and MINORU KOMAI ${ }^{1}$ \\ ${ }^{1}$ Sanshi Group Hikari Clinic, Internal Medicine and Kidney Dialysis, Gunma 379-2201; \\ Departments of ${ }^{2}$ Diagnostic Radiology and Nuclear Medicine, and ${ }^{3}$ Medicine and Clinical Science, \\ Gunma University Graduate School of Medicine, Gunma 371-851, Japan
}

Received June 8, 2010; Accepted July 5, 2010

DOI: $10.3892 / \mathrm{etm} .2010 .122$

\begin{abstract}
The aim of this study was to evaluate the effectiveness of oral iron to manage anemia in long-term hemodialysis (HD) patients using ultrapure dialysate. This study was prospectively conducted on 23 patients (11 males and 12 females; median age 60 years, range 35-81) who underwent HD in our hospital from March to September 2007. The patients were randomly assigned to two treatment groups. The first group of 11 patients received ferrous fumarate $305 \mathrm{mg}$ per oral tablet once a day, while the second group of 12 patients received infusions of $50 \mathrm{mg}$ iron in a $0.9 \%$ sodium chloride solution. At the end of the 6-month treatment, patients receiving oral iron and intravenous iron had a significant increase in transferrin saturation from baseline $(20.1 \pm 8.9$ to $29.7 \pm 7.2$; $\mathrm{p}=0.011$ and $17.4 \pm 6.1$ to $33.7 \pm 8.6 ; \mathrm{p}=0.0001$, respectively) and ferritin $(32.6 \pm 15.4$ to $115.4 \pm 28.2 ; \mathrm{p}=0.0001$ and $57.8 \pm 26.7$ to $183.5 \pm 47.5 ; \mathrm{p}=0.0002$, respectively). In both groups, hemoglobin, hematocrit and dry weight were increased, but did not reach statistical significance. Moreover, both groups showed a significant reduction in the mean weekly erythropoietin dose from baseline $(5,590.9 \pm 1,513.6$ to $3,727.3 \pm 1,618.1 ; \mathrm{p}=0.011$ and $6,775.8 \pm 2,292.2$ to $4,375.0 \pm 2,473.7 ; \mathrm{p}=0.027$, respectively). Oral iron is indeed as effective as intravenous iron in managing anemia in HD patients using ultrapure dialysate.
\end{abstract}

\section{Introduction}

Patients with end stage renal failure (ESRF) develop severe anemia, including those undergoing maintenance hemodialysis (HD). To manage anemia in HD patients, administration of erythropoiesis-stimulating agent (ESA) was widespread in

Correspondence to: Dr Akiyasu Tsuchida, Sanshi Group Hikari Clinic, Internal Medicine and Kidney Dialysis, 1114-Ainoya-machi, Isesaki, Gunma 379-2201, Japan

E-mail: hikari-kn@hikari-cl.jp

Key words: anemia, oral iron, intravenous iron, hemodialysis, ultrapure dialysate the 1990s $(1,2)$. The use of recombinant human erythropoietin (rHuEpo) to treat the anemia of patients on maintenance dialysis has been a major advance in the care of these patients. However, this treatment is frequently blunted for various reasons, including iron deficiency and inflammation (3).

The serum ferritin level and transferrin saturation (TSAT) percentage are the standard laboratory tests used to evaluate iron stores. Both the 1997 and 2001 National Kidney Foundation's anemia guidelines proposed maintaining serum ferritin above $100 \mathrm{ng} / \mathrm{ml}$ and TSAT above 20\% via intermittent or maintenance iron administration $(1,2)$ in patients with chronic renal failure (CRF). Although serum ferritin is a marker of iron status, it is also an acute phase reactant and is consequently influenced by inflammation and infection, which are often present in HD patients.

Previous studies have reported that oral iron therapy cannot meet the demands of ESA in hemodialysis patients due to poor absorption and its interaction with other concurrently used drugs $(4,5)$. Intravenous (IV) iron therapy has been widely used to maintain iron stores and to permit adequate erythropoiesis in HD patients as it is well tolerated by many patients (6-8).

Few reviews have compared oral vs. IV iron in HD patients. A recent systemic review and meta-analysis suggested that patients treated with IV iron have better hemoglobin $(\mathrm{Hb})$ levels than those treated with oral iron (9). However, some studies have found that oral iron is well tolerated and effective in long-term HD patients (10) and as effective as IV iron in pre-dialysis patients $(11,12)$. The appropriate and standard method of iron supplementation in managing anemia in HD patients is still under debate.

Chronic inflammation is now believed to decrease iron absorption from the gut through increased hepcidin synthesis (13). Hepcidin, a serum protein, is produced by the liver and is a key regulator of iron mobilization. In HD patients, bacterial contamination of the dialysate leads to increased inflammatory cytokine production and chronic inflammation $(14,15)$. Therefore, we hypothesized that sterile dialysate may improve the effect of oral iron supplementation on erythropoiesis. In this study, we prospectively evaluated the effectiveness of oral and IV iron for the management of anemia using ultrapure dialysate in randomly selected HD patients. 


\section{Heat Disinfection System}

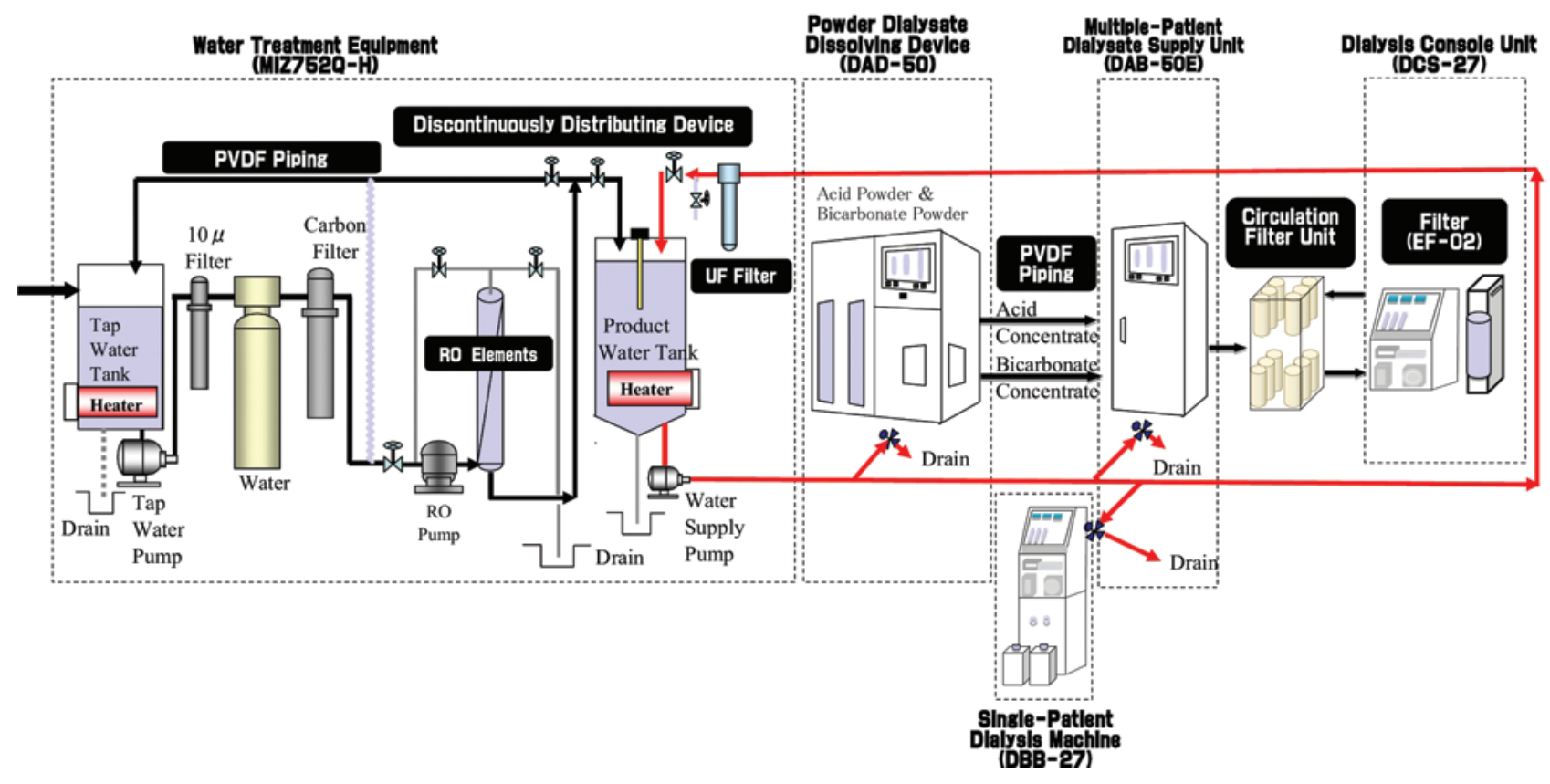

Figure 1. Layout diagram of the water treatment equipment of our hospital showing the cleaning and dysfunction system.

\section{Materials and methods}

Patients and treatment. This study was conducted in compliance with the declaration of Helsinki. The institutional review board approved the study protocol, and written informed consent was obtained from all of the patients. A total of 24 consecutive HD patients treated at our hospital were selected prospectively from March to September 2007. One patient was transferred to another hospital due to personal reasons and was therefore excluded from the study. Twenty-three patients (11 males and 12 females; median age 60 years, range $35-81$ ) were finally included. Patients were then randomly assigned to two treatment groups. The first group of 11 patients received oral ferrous fumarate $305 \mathrm{mg}$ (equivalent to $100 \mathrm{mg} \mathrm{Fe}$ ) (Nichi-iko Pharmaceutical Co. Ltd., Tokyo, Japan) once a day, while the second group of 12 patients received IV infusions of cideferron (50 mg Fe in $2 \mathrm{ml}$ ) (Nippon Zoki Pharmaceutical Co. Ltd., Tokyo, Japan). Cideferron (2 ml) was diluted in $100 \mathrm{ml}$ of a $0.9 \%$ sodium chloride solution and was infused during HD once a week. The patients were administered rHuEpo (Epoetin- $\beta$; Chugai Pharmaceutical Co. Ltd, Tokyo, Japan) intravenously at the end of HD. The rHuEpo dose was individually adjusted to maintain a target hematocrit (Hct) of $33-38 \%$.

The inclusion criteria included i) patients with anemia, ii) patients on regular hemodialysis for $>6$ months, and iii) patients testing negative for occult blood in stool. Excluding criteria included i) patients with active infection, ii) patients with uncontrolled hypertension, iii) patients with a history of coronary artery disease, iv) patients who changed treatment options from oral to IV or vice-versa or who were awaiting renal transplantation, v) pregnant or lactating women, and vi) patients who received a blood transfusion within 1 month prior to the study. Patients were permitted to withdraw from the study at any time for any reason and were not replaced.

Efficacy endpoints and clinical assessments. The primary purpose of the study was to evaluate the efficacy of oral iron and IV iron for the management of anemia. Efficacy was evaluated by an improvement in iron deficiency, such as an increase in TSAT, serum ferritin, Hct or $\mathrm{Hb}$, and a reduction in the mean weekly erythropoietin dose. Changes in dry weight (DW) and cardiothoracic ratio (CTR) were also evaluated. $\mathrm{Hb}$, Hct and creatinine were measured twice a month. DW and CTR were measured on a monthly basis. TSAT, serum ferritin, serum iron, $\beta 2$-microglobulin $(\beta 2-\mathrm{MG})$ and total iron binding capacity (TIBC) were measured once every 6 months. Patients were closely monitored for gastrointestinal symptoms, including indigestion, abdominal pain and constipation. Stool specimens were checked for fecal occult blood before treatment, every 3 months, and whenever there was a clinical suspicion of gastrointestinal hemorrhage.

Dialysate cleaning system. At our hospital, the dialysate was cleaned using water treatment equipment with the reverse osmosis (RO) module MIZ752Q-H (Japan Water System Co, Tokyo, Japan), the newest model in the series (Nikkiso Co. Ltd., Tokyo, Japan), as shown in Fig. 1. The system is equipped with the most recent reverse osmosis module, polyvinylidene difluoride piping, RO water lines, automatic flushing within the equipment and daily automatic disinfection system. Disinfection is performed using peracetic acid and calcium hydrochloride in combination with the heat treatment of water by boiling it at $83^{\circ} \mathrm{C}$ and allowing it to be circulated for $60 \mathrm{~min}$ throughout the entire piping system that comes into contact with the dialysis solutions. The system was operated auto- 
Table I. Baseline characteristics of the 23 patients.

\begin{tabular}{|c|c|c|c|}
\hline Characteristics & $\begin{array}{l}\text { All patients } \\
\qquad(\mathrm{n}=23)\end{array}$ & $\begin{array}{l}\text { Oral iron group } \\
\qquad(\mathrm{n}=11)\end{array}$ & $\begin{array}{l}\text { IV iron group } \\
(n=12)\end{array}$ \\
\hline Age (years) & $60.3 \pm 11.9$ & $59.5 \pm 10.7$ & $61 \pm 13.3$ \\
\hline \multicolumn{4}{|l|}{ Gender } \\
\hline Male & 11 & 5 & 6 \\
\hline Female & 12 & 6 & 6 \\
\hline Duration of dialysis (months) & $98.4 \pm 80.4$ & $114 \pm 93.6$ & $85.7 \pm 68.4$ \\
\hline \multicolumn{4}{|l|}{ Primary renal disorders } \\
\hline Diabetic nephropathy & 12 & 6 & 6 \\
\hline Chronic glomerulonephrites & 9 & 4 & 5 \\
\hline Renal sclerosis & 1 & 0 & 1 \\
\hline
\end{tabular}

Table II. Outcome of different parameters before and after the therapy of the 23 patients.

\begin{tabular}{|c|c|c|c|c|c|c|}
\hline \multirow[t]{2}{*}{ Variables } & \multicolumn{3}{|c|}{ Oral iron $(n=11)$} & \multicolumn{3}{|c|}{ IV iron $(n=12)$} \\
\hline & Before therapy & After therapy & p-value & Before therapy & After therapy & p-value \\
\hline TSAT (\%) & $20.09 \pm 8.92$ & $29.73 \pm 7.24$ & 0.0110 & $17.42 \pm 6.10$ & $33.75 \pm 8.64$ & 0.0001 \\
\hline Serum ferritin (ng/ml) & $32.64 \pm 15.45$ & $115.36 \pm 28.18$ & 0.0001 & $57.75 \pm 26.68$ & $183.5 \pm 47.53$ & 0.0002 \\
\hline Serum iron $(\mu \mathrm{g} / \mathrm{dl})$ & $57.8 \pm 26.4$ & $59.2 \pm 23.5$ & 0.9000 & $55.5 \pm 15.8$ & $67.3 \pm 16$ & 0.0210 \\
\hline Serum TIBC $(\mu \mathrm{g} / \mathrm{dl})$ & $245.9 \pm 41.6$ & $236 \pm 36.3$ & 0.6100 & $259 \pm 40$ & $218.4 \pm 47.6$ & 0.0600 \\
\hline$\beta 2-\mathrm{MG}(\mathrm{mg} / \mathrm{l})$ & $31.1 \pm 7.7$ & $28.7 \pm 4.7$ & 0.3900 & $26.1 \pm 2.3$ & $24.1 \pm 6.8$ & 0.6900 \\
\hline Creatinine (mg/dl) & $11.2 \pm 2.3$ & $11.1 \pm 2.1$ & 0.8600 & $9.4 \pm 2.8$ & $9.3 \pm 2.6$ & 0.9500 \\
\hline Hemoglobin (g/dl) & $10.16 \pm 1.28$ & $11.1 \pm 0.6$ & 0.0620 & $9.57 \pm 1.64$ & $10.74 \pm 1.09$ & 0.0510 \\
\hline Hematocrit $(\%)$ & $33.47 \pm 2.67$ & $35.4 \pm 2.53$ & 0.0970 & $30.98 \pm 5.17$ & $34.38 \pm 3.47$ & 0.0700 \\
\hline Dry weight (kg) & $55.15 \pm 8.11$ & $55.98 \pm 7.13$ & 0.8100 & $57.86 \pm 17.09$ & $57.98 \pm 16.69$ & 0.9800 \\
\hline CTR $(\%)$ & $49.73 \pm 5.24$ & $48.44 \pm 4.76$ & 0.5500 & $48.03 \pm 2.54$ & $48.78 \pm 3.23$ & 0.5200 \\
\hline Erythropoeitin (IU/week) & $5,590.91 \pm 1,513.58$ & $3,727.27 \pm 1,618.08$ & 0.0110 & $6,775.83 \pm 2,292.23$ & $4,375.00 \pm 2,473.73$ & 0.0240 \\
\hline
\end{tabular}

IV, intravenous; TSAT, transferrin saturation; TIBC, total iron binding capacity; $\beta 2-\mathrm{MG}, \beta 2$-microglobulin; CTR, cardiothoracic rate.

matically every day, enabling the hygienic mixing of solutions within an entirely enclosed piping system. The heat disinfection was performed $2.5 \mathrm{~h}$ before dialysis, which allowed the optimal temperature of the dialysate to be administered into the patients. The crevice-free adhesion method allows pipes to be joined together without creating a difference in level between the two pipes, thus reducing the problem of microorganisms adhering to and multiplying in the joints between pipes. Therefore, in our clinic, we assure safety by providing an outstandingly clean dialysate. This model provides a superior level of cleanliness to the processing water.

Bacteriological analysis. Bacterial analysis was performed by trained staff three times a week by collecting the dialyzed samples from different sites of the circulation system. The bacterial count was evaluated by a pour-plate method using Trypticase Soy Agar at 20 and $37^{\circ} \mathrm{C}$ for at least 5 days. Testing for fecal indicator bacteria, such as fecal coliforms, enterococci and pseudomonas aeruginosa, was conducted. Endotoxin concentrations were measured using a chromogenic limulus amebocyte lysate assay (Mini-LAL kit; Wako Junyaku, Osaka, Japan) by the kinetic turbidimetric method (LAL-5000; Associates of Cape Cod, MA, USA). This test system is calibrated in endotoxin units (EU) per ml. The detection limit was $0.03 \mathrm{EU} / \mathrm{ml}$.

Statistical analysis. Data were expressed as the mean \pm standard deviation. The paired Student's t-test was used to evaluate the changes from baseline of each group, and the unpaired t-test was used to compare the changes between the oral and IV iron groups. Probability values of $<0.05$ were considered statistically significant.

\section{Results}

Efficacy. The baseline characteristics of the different parameters are summarized in Table I. At the end of the 6-month treatment, patients receiving oral iron had a significant increase from the baseline value of TSAT $(20.09 \pm 8.92$ to $29.73 \pm 7.24 ; \mathrm{p}=0.011)$ and ferritin $(32.64 \pm 15.45$ to $115.36 \pm 28.18 ; \mathrm{p}=0.0001)$. On the other hand, patients 
receiving IV iron had a significant increase from the baseline value of TSAT $(17.42 \pm 6.1$ to $33.75 \pm 8.64 ; \mathrm{p}=0.0001)$, ferritin $(57.75 \pm 26.68$ to $183.5 \pm 47.53 ; \mathrm{p}=0.0002)$ and serum iron $(55.5 \pm 15.8$ to $67.3 \pm 16 ; \mathrm{p}=0.021)$. In both treatment groups, $\mathrm{Hb}$, Hct and DW were increased, but did not reach statistical significance, as shown in Table II. Patients receiving oral iron and IV iron had a significantly decreased erythropoietin dose from baseline $(5,590.91 \pm 1,513.58$ to $3,727.27 \pm 1,618.08$; $\mathrm{p}=0.011$ and $6,775.83 \pm 2,292.23$ to $4,375.0 \pm 2,473.73 ; \mathrm{p}=0.027$, respectively). TIBC, $\beta 2-\mathrm{MG}$, creatinine and $\mathrm{CTR}$ tended to decrease in both treatment groups, but did not reach statistical significance. We also analyzed changes after therapy of the different parameters between the two treatment groups, and found no statistically significant differences in any of the parameters (data not shown).

Safety. Three patients in the oral iron group and 1 patient in the IV iron group were reported to have a mild or moderate gastrointestinal disorder; however, it was tolerated and was corrected with diet. There were no deaths or severe adverse effects during the study, nor did any patients discontinue the study due to drug-related side effects.

Quality of dialysate. The results of the microbacterial analysis from the dialyzed sample consistently showed a bacterial count of $<0.1$ colony forming units (cfu) per $\mathrm{ml}$ and EU of $<0.03$ (data not shown). According to the Japanese Society for Dialysis Therapy, the bacterial count should be $<100 \mathrm{cfu} / \mathrm{ml}$ in standard dialysate and $<0.1 \mathrm{cfu} / \mathrm{ml}$ in ultrapure dialysate (16). Thus, our clinic provided ultrapure dialysate for HD patients on a routine basis.

\section{Discussion}

The results of the present study suggest that oral iron is as effective as IV iron in managing anemia in CRF patients undergoing HD using ultrapure dialysate. The baseline value of TSAT and ferritin was significanlty increased in each group. In addition, the mean weekly erythropoietin dose was significantly decreased from the baseline in each group, indicating that oral iron may indeed be as effective as IV iron.

Previous studies have reported that patients undergoing HD showed a better response to IV iron; however, patients with CRF showed no difference between oral and IV iron (9). Another study demonstrated that IV and oral iron caused a similar correction in anemia over 6 weeks (17). Several studies have reported that IV iron has greater efficacy with rHuEpo than oral iron, perhaps as a result of reduced iron absorption from the gut and poor patient compliance with oral medication $(4-8,18)$. Although new formulations of IV iron have drastically reduced the risk of immediate adverse effects, a variety of long-term consequences of IV iron have been reported in the literature $(15,19)$. Furthermore, several studies have demonstrated that the administration of IV iron releases free iron, which may react with hydrogen peroxide to produce hydroxyl radical oxidants and may lead to increased oxidative stress that can potentially damage cellular lipids, nucleic acids, proteins and carbohydrates $(20,21)$. IV iron bypasses the physiologic controls of iron absorption and storage, thereby exposing the patient to higher levels of circulating free iron and higher tissue levels of iron. A number of authors recently reviewed the link between free or stored iron and a variety of disease states, including cardiovascular disease $(18,22)$, carcinogenesis $(19,23)$ and infection $(15,24)$.

The chemical and microbiological quality of water used in dialysate plays a crucial role in the mortality and morbidity of patients on HD. During dialysis, a patient receives 90-150 1 of water a day; insufficient chemical and microbiological quality of water leads to infections. Beside cardiovascular disease, infection is the most common cause of death in dialysis patients. Endotoxin derived from gram-negative bacteria may penetrate the dialyser membrane and may be responsible for a pyrogenic reaction (25). Thus, we speculate that the highly ultrapure dialysate used for HD in our clinic contributed to the proper utilization of oral iron absorption from the gut by controlling intestinal inflammation, and ensured the control of anemia through oral iron supplementation.

The present study showed that, by using ultrapure dialysate, oral iron improves iron deficiencies and significantly reduces the erythropoietin dose from the baseline, similarly to IV iron. As oral iron is less expensive, safer and easier to administer, and equally or more competent as IV iron, the use of oral iron as a first-line therapy is preferred. However, IV iron should be considered as an alternative for patients who do not tolerate oral iron or for whom iron deficiency persists despite an adequate dose of oral iron. There are a few limitations to our study. The total population of the patients was small, and the period of observation for efficacy was short. The erythropoietin dose administered was not the same in the two treatment groups; rather it was modified depending on the Hct level.

In summary, with the help of ultrapure dialysate, oral iron is indeed as effective as intravenous iron in managing anemia in HD patients, as it maintains the iron indices and is well tolerated. Our hospital currently focuses on the use of oral iron supplementation as a first-line therapy to control anemia in ESRF patients undergoing HD.

\section{Acknowledgements}

We thank Mr. Takahiro Nakama (Nikkiso Comp. Ltd., Tokyo, Japan) and Mr. Takenori Suzuki (JWS Comp., Tokyo, Japan) for help with making the layout figure of the water treatment equipment. We also thank Mr. Kenichi Nishimura, Ms. Junko Imaizumi and Ms. Taeko Kobayashi of the Sanshi Group Hikari Clinic for their expertise. Part of the data was presented at the 53rd Congress of the Japanese Society of Dialysis and Treatment, Kobe, Japan.

\section{References}

1. Van Wyck D, Eckardt KU, Uhlig K, Rocco M and Levin A: Appraisal of evidence and control of bias in the kidney disease outcomes quality initiative guideline development process. Clin J Am Soc Nephrol 2: 8-10, 2007.

2. Fishbane S, Kalantar-Zadeh K and Nissenson AR: Serum ferritin in chronic kidney disease: reconsidering the upper limit for iron treatment. Semin Dial 17: 336-341, 2004.

3. Kalantar-Zadeh K, McAllister CJ, Lehn RS, Lee GH, Nissenson AR and Kopple JD: Effect of malnutritioninflammation complex syndrome on EPO hyporesponsiveness in maintenance hemodialysis patients. Am J Kidney Dis 42: $761-773,2003$ 
4. Fishbane S and Maesaka JK: Iron management in end-stage renal disease. Am J Kidney Dis 29: 319-333, 1997.

5. Wingard RL, Parker RA, Ismail N and Hakim RM: Efficacy of oral iron therapy in patients receiving recombinant human erythropoietin. Am J Kidney Dis 25: 433-439, 1995.

6. Kapoian T, O'Mara NB, Singh AK, et al: Ferric gluconate reduces epoetin requirements in hemodialysis patients with elevated ferritin. J Am Soc Nephrol 19: 372-379, 2008.

7. Macdougall IC: Intravenous administration of iron in epoetintreated haemodialysis patients - which drugs, which regimen? Nephrol Dial Transplant 15: 1743-1745, 2000.

8. Coyne DW, Kapoian T, Suki W, et al: Ferric gluconate is highly efficacious in anemic hemodialysis patients with high serum ferritin and low transferrin saturation: results of the Dialysis Patients' Response to IV Iron with Elevated Ferritin (DRIVE) Study. J Am Soc Nephrol 18: 975-984, 2007.

9. Rozen-Zvi B, Gafter-Gvili A, Paul M, Leibovici L, Shpilberg O and Gafter U: Intravenous versus oral iron supplementation for the treatment of anemia in CRF: systematic review and metaanalysis. Am J Kidney Dis 52: 897-906, 2008.

10. Lenga I, Lok C, Marticorena R, Hunter J, Dacouris N and Goldstein M: Role of oral iron in the management of long-term hemodialysis patients. Clin J Am Soc Nephrol 2: 688-693, 2007.

11. Stoves J, Inglis $H$ and Newstead CG: A randomized study of oral vs intravenous iron supplementation in patients with progressive renal insufficiency treated with erythropoietin. Nephrol Dial Transplant 16: 967-974, 2001.

12. Charytan C, Qunibi W and Bailie GR: Comparison of intravenous iron sucrose to oral iron in the treatment of anemic patients with chronic kidney disease not on dialysis. Nephron Clin Pract 100: 55-62, 2005.

13. Muñoz M, Villar I and García-Erce JA: An update on iron physiology. World J Gastroenterol 15: 4617-4626, 2009.

14. Pérez-García R, Martín-Malo A, Fort J, et al: Baseline characteristics of an incident haemodialysis population in Spain: results from ANSWER - a multicentre, prospective, observational cohort study. Nephrol Dial Transplant 24: 578-588, 2009.
15. Malyszko $\mathbf{J}$ and Mysliwiec $\mathbf{M}$ : Hepcidin in anemia and inflammation in chronic kidney disease. Kidney Blood Press Res 30: 15-30, 2007.

16. Nakai S, Masakane I, Shigematsu T, et al: An overview of regular dialysis treatment in Japan (as of 31 December 2007). Ther Apher Dial 13: 457-504, 2009.

17. Agarwal R, Rizkala AR, Bastani B, Kaskas MO, Leehey DJ and Besarab A: A randomized controlled trial of oral versus intravenous iron in chronic kidney disease. Am J Nephrol 26: 445-454, 2006.

18. Boddy K, Lawson DH, Linton AL and Will G: Iron metabolism in patients with chronic renal failure. Clin Sci 39: 115-121, 1970.

19. Hezode C, Cazeneuve C, Coue O, et al: Liver iron accumulation in patients with chronic active hepatitis $\mathrm{C}$ : prevalence and role of hemochromatosis gene mutations and relationship with hepatic histological lesions. J Hepatol 31: 979-984, 1999

20. Lim PS, Wei YH, Yu YL and Kho B: Enhanced oxidative stress in haemodialysis patients receiving intravenous iron therapy. Nephrol Dial Transplant 14: 2680-2687, 1999.

21. Nascimento MM, Suliman ME, Bruchfeld A, et al: The influence of hepatitis $\mathrm{C}$ and iron replacement therapy on plasma pentosidine levels in haemodialysis patients. Nephrol Dial Transplant 19: 3112-3116, 2004

22. Feldman HI, Santanna J, Guo W, et al: Iron administration and clinical outcomes in hemodialysis patients. J Am Soc Nephrol 13: 734-744, 2002.

23. Williams P and Griffiths E: Bacterial transferrin receptors structure, function and contribution to virulence. Med Microbiol Immunol 181: 301-322, 1992.

24. Patruta SI, Edlinger R, Sunder-Plassmann G and Hörl WH: Neutrophil impairment associated with iron therapy in hemodialysis patients with functional iron deficiency. J Am Soc Nephrol 9: 655-663, 1998

25. Lonnemann G, Krautzig S and Koch KM: Quality of water and dialysate in haemodialysis. Nephrol Dial Transplant 11: 946-949, 1996. 